International Journal of Automotive and Mechanical Engineering (IJAME)

ISSN: 2229-8649 (Print); ISSN: 2180-1606 (Online)

Volume 12, pp. 3003-3017, July-December 2015

CUniversiti Malaysia Pahang

DOI: http://dx.doi.org/10.15282/ijame.12.2015.15.0250

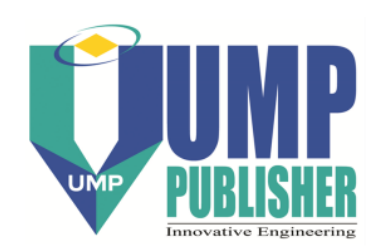

\title{
Multi-objective optimization of minimum quantity lubrication in end milling of aluminum alloy AA6061T6
}

\author{
M.S. Najiha1, M.M. Rahman ${ }^{2,3 *}$, K. Kadirgama ${ }^{2}$, M.M. Noor ${ }^{2}$ and D. Ramasamy ${ }^{2}$ \\ ${ }^{1}$ International Affairs and training Division \\ Pakistan Atomic Energy Commission, Karachi, Pakistan \\ ${ }^{2}$ Faculty of Mechanical Engineering, Universiti Malaysia Pahang, \\ 26600 Pekan, Pahang, Malaysia \\ Email: mustafizur@ump.edu.my \\ Phone: +6094262239; Fax: +6094246222 \\ ${ }^{3}$ Automotive Engineering Centre, Universiti Malaysia Pahang, \\ 26600 Pekan, Pahang, Malaysia
}

\begin{abstract}
The purpose of this research is to optimize the process of minimum quantity lubrication (MQL) in the end milling of AA6061T6 using multi-objective genetic algorithm approach. Response surface methodology coupled with a central composite design of experiments is used for modeling. Data is collected from a vertical CNC milling center and the input parameters are cutting speed, table feed rate, axial depth of cut and the minimum quantity lubrication flow rate. Analysis of variance at a $95 \%$ confidence level is implemented to identify the most significant input variables on the $\mathrm{CNC}$ end milling process. Optimization of the responses is done using a multi-objective genetic algorithm. A multi-criteria decision making utility is used to find among the feasible range of optimum designs for the operating parameters and the responses. An iterative multi-criteria decision making algorithm is used to find the best design among those obtained from multiobjective optimization with respect to the given conditions. The best design obtained for the equal weightage case is the design at $5252 \mathrm{rpm}$, with a feed rate of $311 \mathrm{~mm} / \mathrm{min}$, a depth of cut of 3.47 $\mathrm{mm}$ and MQL flow rate at $0.44 \mathrm{ml} / \mathrm{min}$.
\end{abstract}

Keywords: MQL; multi-objective optimization; aluminum alloy; Pareto; optimal design.

\section{INTRODUCTION}

Minimum quantity lubrication has been demonstrated to be an effective near dry machining technique as well as an efficient alternative to completely dry and wet cutting conditions from the viewpoint of cost, ecological and human health issues and machining process performance[1]. MQL is a sustainable manufacturing technique that is safe for the environment and the worker and is cost effective [2-5]. The cost of cutting fluids range from 7 to $17 \%$ of the total machining cost while another estimate gives this cost as $15-20 \%$ of total machining cost compared to the tool cost which ranges from 2 to $4 \%$ [6-11]. Therefore minimization of metal working fluids can serve as a direct indicator of sustainable manufacturing. The goal of MQL is to machine parts using a minimal amount of metal working fluids, typically of a flow rate of $50-500 \mathrm{ml} / \mathrm{h}$, which are about three to four orders of magnitude less than the amount commonly used in the flood cooling 
condition [12-14] so that the workpiece, chips and environment remain dry after cutting. The concept of minimum quantity lubrication, sometimes referred to as near dry lubrication [15] or microlubrication [16], was first suggested a decade ago as a means of addressing the issues of environmental intrusiveness and occupational hazards associated with the airborne cutting fluid particles on factory shop floors. In the recent past, there has been a general preference for dry machining [17]. On the other hand, several researchers have started exploring the application of minimal cutting fluid. Minimum quantity lubrication offers considerable advantages over both the conventional traditional wet machining processes and dry machining. The machined parts are lubricated with a very small amount of fluid sprayed on to them, resulting in a very low residue of lubricant on chips, tool and the workpiece; hence their cleaning is easier and cheaper; recycling of chips is easy, as is scrutiny of the machining process, since the machining area is not flooded. Machining with MQL has been extensively applied in many machining processes such as drilling [18-20], milling [21-26], turning [19, 27], and MQL grinding [28-31]. MQL is significantly contributing towards performance and quality in the environment, working condition and economics of machining. Since it does not require power-consuming auxiliary equipment like compressors, pumps and chillers, as are used in a flooded lubricating system, it significantly reduces energy consumption. Besides environmental and health issues, costs associated with the applications, storage and disposal of cutting fluids are also a concern. About $15 \%-20 \%$ of the overall machining costs are related to cooling and lubricating fluids $[5,8,32]$. The annual global consumption of cutting fluids by the year 2007 was 640 million gallons [4]. Considering the high costs associated with cutting fluids and the associated occupational exposure, it is essential to find a cost-effective approach to manufacture products. Several researches conducted on the application of MQL in machining of steel have been reported [6, 13, 23, 33-39]. The results of these studies have exhibited that MQL may be considered as a potential environment compatible as well as economic lubrication technique. Most of the researches involved machining with MQL, as cutting medium, have been concerned mainly with the turning, drilling and grinding process. There have been very few articles published which use MQL in end milling [40]. The usual practice in end milling process is the application of abundant amounts of liquid coolant, with the liquid coolant as intermittent cooling increases the temperature variations [41] and build up edge [42]. Hence simply cutting-off the amount of coolant used is not a practical answer for end milling due to the intermittent nature of cutting action at the tool tip resulting in increased temperature variations at the tip of the tool. Thus, the role of MQL as a potential method is still to be explored for minimizing the consequences of thermal shock in end milling for removing the generated heat during the entire cutting cycle.

MQL has been effective in prolonging tool life when machining steel specimens [43]. However there has not been the same rigorous investigations into the machining of Al alloys [42]. Conflicting views about the cooling conditions for the alloy are observed in literature. Cutting fluids are normally considered not necessary when machining aluminium alloys on account of relatively low cutting temperatures [44]. However, highly effective lubrication is required for aluminium alloys on account of high adhesive characteristics [45]. Unlike steel and other metals, cutting fluids are essential for $\mathrm{Al}$ alloys machining in order to minimize the smearing effects on the cutting tool edges and to reduce the surface roughness. There are few technical issues still related to aluminium machining which need to be resolved such as tool wear and machine reliability. The principal wear mechanisms in Al alloys machining are burr formation, built-upedge as well as surface roughness. Surface finish and burr formation in aluminium alloy machining are mainly used as tool life criteria as it is difficult to observe tool wear in aluminium alloys 
machining [42]. However, to achieve high cooling ability with MQL, a fluid with high thermal conductivity must be selected. Cooling is one of the most important challenges in the machining process [46]. The conventional methods of enhancing the cooling rate have already exhausted to their limits [47]. Keeping in view the above-mentioned challenges presented in machining processes, use of new and innovative cutting fluids is highly desirable in order to achieve high performance cooling. MQL is a more practical approach in comparison with flooded and dry machining. With MQL, when properly applied, both parts and chips remain dry and are easier to handle [48]. It therefore makes recycling of the metal chips easier. MQL is an achievementoriented technology, which replaces conventional lubrication techniques and takes over the lubrication task, assisting in sustainable development, with mechanical manufacturing processes. Most of the research conducted with respect to minimum quantity lubrication and related issues sets out to show the overall advantages of MQL as opposed to the use of a conventional emulsion coolant, and there have been several successful experiments using it in the machining of different materials. The real objective in sustainable machining is to produce the parts using an optimized minimum quantity of metal working fluids so that the workpiece, chips and environment remain dry after cutting. In order to fulfill this objective, optimum machining parameters are of immense significance in the machining performance for efficient use of costly machine tools. In most cutting operations, the cutting parameters are set according to the operating range recommended by the handbooks. The task is to find the optimum cutting parameters for efficient inexpensive machining. Many researches have been conducted to optimize machining parameters, but most of these are for optimizing turning operations; however, other machining operations, including milling, have attracted little interest [49]. End milling is one of the most widely used metal removal operations in industry because of its ability to remove material faster, giving a reasonably good surface finish [50]. Owing to the significant role that milling operations play in today's manufacturing world, there is a vital need to optimize machining parameters for this operation, particularly when CNC machines are employed. Significance of machining processes optimization arises from the prerequisite for an economic and feasible performance of the machining processes. Practical manufacturing processes are illustrated by conflicting and often incompatible measures of performance such as quality and productivity [51]. The multi-objective optimization techniques are used to find out trade-offs among the conflicting performance measures in a machining process in order to achieve performance optimization. In such cases, it is not necessary that a single solution may satisfy all the objectives on account of incommensurability and the conflict among the objectives. Multi-objective optimization is different from single objective optimization in that the single objective optimization is used to find the best design from among many and usually best design point is the global maximum or minimization depending on the type of optimization [52]. The purpose of this study is to optimize the process of minimum quantity lubrication in the end milling of aluminum alloy AA6061T6. Experiments have been conducted using a central composite design approach. The results obtained have been used to investigate which parameters are the most significant and effective in end milling with the minimum quantity lubrication technique. Genetic algorithm is implemented for the optimization of the end milling parameters. Genetic algorithm is quite successful in the optimization of the machining parameters and especially the turning parameters [49]. A multi-objective genetic algorithm based approach is used in this work for the end milling operation assumed as a constrained optimization problem. Multiobjective optimization problems usually have many optimal solutions, known as Pareto optimal solutions [53]. The algorithm attempts a total number of evaluations that is equal to the number of points in the design of experiment (DOE) table (the initial population) multiplied by the number 
of generations. The specimen surface roughness, material removal rate and flank wear are used as the objective functions in a single pass end milling constrained parameter optimization problem. A commercial non-toxic type of renewable vegetable oil-based cutting fluid (Coolube 2210 ,UNIST, Inc.) is used. The experiments were designed according to a central composite design under minimum quantity lubrication conditions. The perthometer is used to obtain the average surface roughness $\mathrm{R}_{\mathrm{a}}$. Statistical quadratic models of the surface roughness and material removal rate are used to fit the experimental data of the surface roughness.

\section{METHODOLOGY}

\section{Machining Parameters and Design of Experiments}

The machining parameters selected in this research are spindle speed, table feed rate, depth of cut and the minimum quantity lubricant flow rate. The central composite design approach of response surface methodology is used for the design of experiments in order to find the effects and the combination of the parameters. Five levels of machining variables are selected, as shown in Table 1.

Table 1. Assignment of the levels to machining parameters.

\begin{tabular}{lccccc}
\hline Factors & \multicolumn{5}{c}{ Levels } \\
\cline { 2 - 6 } & 1 & 2 & 3 & 4 & 5 \\
\hline Cutting speed $(\mathrm{rpm})$ & 5252.0 & 5300.0 & 5400.0 & 5500.0 & 5548.0 \\
Depth of cut, $(\mathrm{mm})$ & 288.0 & 318.0 & 379.0 & 440.0 & 469.0 \\
Table feed rate, $(\mathrm{mm} / \mathrm{min})$ & 0.37 & 1.00 & 2.00 & 3.00 & 3.63 \\
MQL flow rate $(\mathrm{ml} / \mathrm{min})$ & 0.39 & 0.48 & 0.65 & 0.83 & 1.00 \\
\hline
\end{tabular}

\section{Measurement of Parameters}

The response variables studied in this research are surface roughness, material removal rate and tool flank wear. Surface roughness and material removal rate are the two conflicting responses of the experiments. Surface roughness is measured using a perthometer (MarSurf XR 20 (Mahr)) while the material removal rate is calculated by weighing the workpiece after every single cut. Surface roughness $\left(R_{a}\right)$ is measured in $\mu \mathrm{m}$. Flank wear is measured in $\mu \mathrm{m}$ with a scanning electron microscope.

\section{Workpiece, Cutting Tool and Cutting Fluid}

The specimen workpiece material used is AA6061T6 aluminum alloy, which is a commonly used commercial alloy with wide-ranging applications in industry on account of its good machinability and continuous chips. The workpiece has the dimensions $100 \mathrm{~mm} \times 100 \mathrm{~mm} \times 30 \mathrm{~mm}$. Workpieces from the same batch were used in the experiments. $\mathrm{Si}, \mathrm{Cu}$ and $\mathrm{Mg}$ are the main constituents of the alloy. The density of the alloy used for calculating the material removal rate is $2712 \mathrm{~kg} / \mathrm{m}^{3}$. An uncoated tungsten carbide end mill with two flutes is selected for the machining. Experiments are designed using a central composite design methodology and a quadratic response surface model is applied. Optimization is carried out to find the best design. Analysis of variance (ANOVA) is utilized to verify the adequacy of the experimental data. A commercial non-toxic type of renewable vegetable oil-based cutting fluid (Coolube 2210, UNIST, Inc.) is used. Experiments are performed using a vertical CNC milling center, the HAAS VF6. The blank and machined workpiece as well 
as machining pattern on the specimen is shown in Figure 1. Setting up of workpiece on the machine is shown in Figure 2.

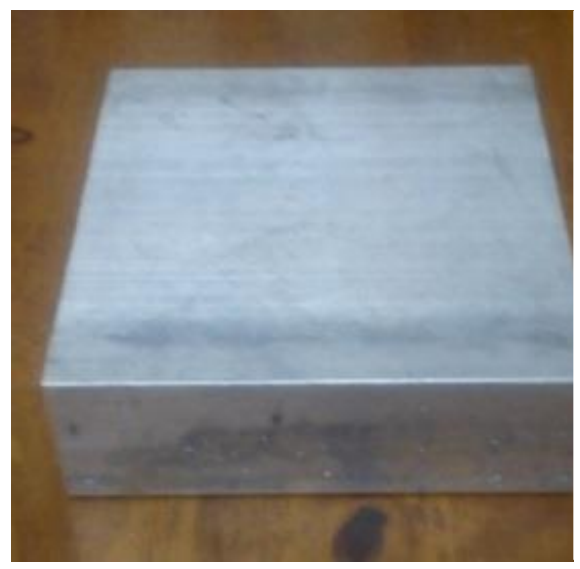

(a) Blank workpiece

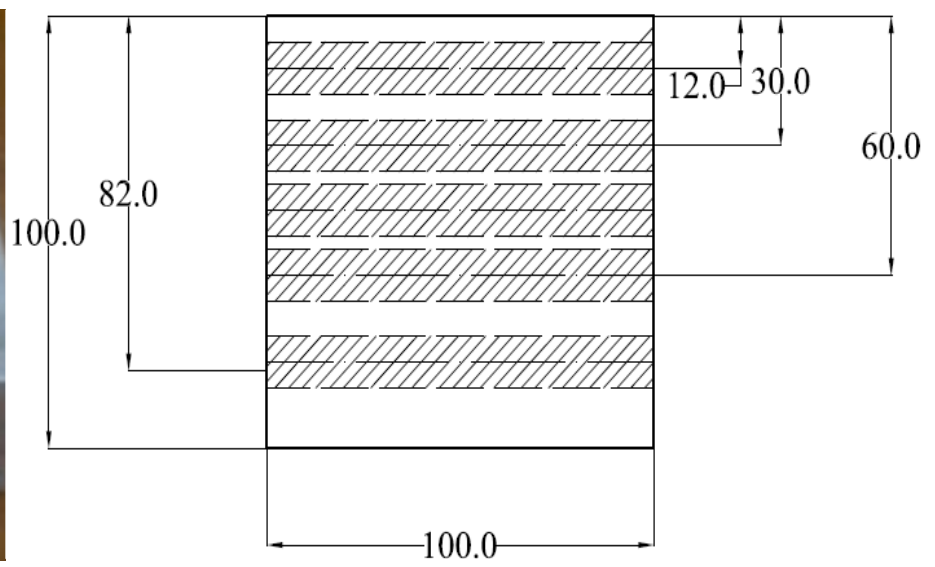

(b) Machined dimension ( $\mathrm{mm})$

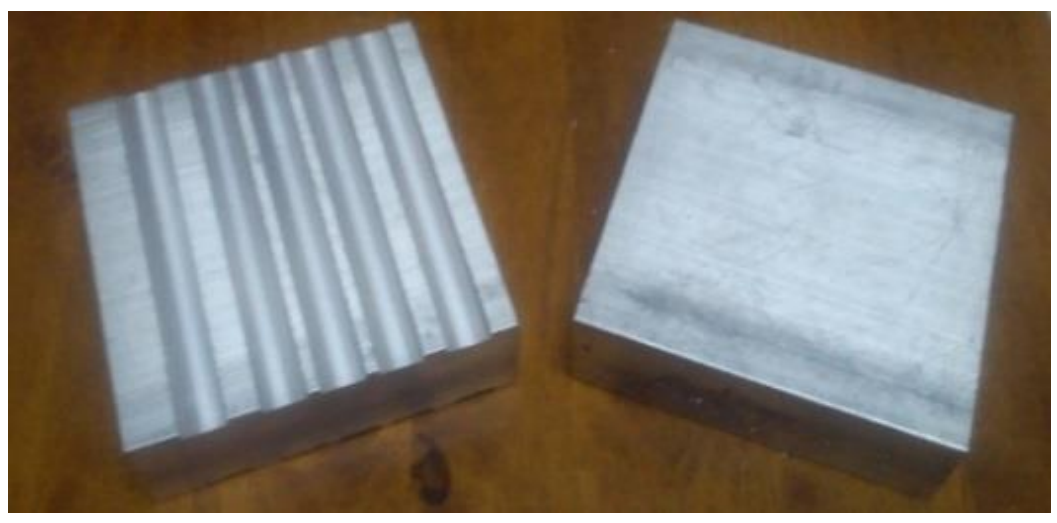

(c) Machining workpiece

Figure 1. Workpiece blank and machined workpiece with dimensions in $\mathrm{mm}$.

\section{MQL System}

MQL is delivered to the cutting zone through the UNIST Uni-MAX coolubricator system. The mist system consists with coaxial nozzles for air and lubricant mixing maintaining constant rate of atomization; continuous external lubrication through automatic cycles of metering pump, a variable rate pulse generator (4-200 pulse/minute) powered by air pressure and flexible nozzle providing flexibility in positioning. The pulse generator produces repetitive cycles of the metering pump. A 1-drop meter output 6-nozzles configuration is used. The system is provided with six positive displacement oil metering pumps (0.2-1.00 $\mathrm{ml} /$ stroke) with adjustable stroke and output. An air metering pump is used to control air flow for atomization. The different components of the MQL system are shown in Figure 3. MQL flow rate is adjusted by setting the stroke length as 10 while the flow rate is adjusted by indexing the flow rate according to counter clockwise turnings. 


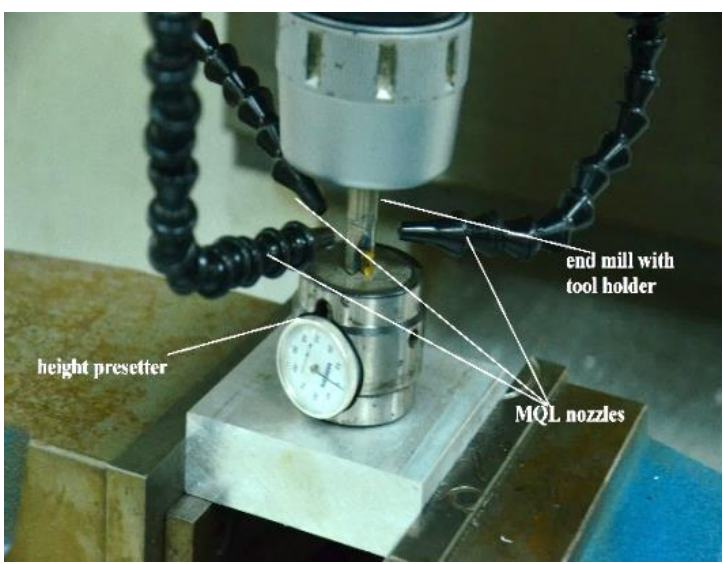

(a) Height compensation setting using $\mathrm{z}^{-}$ presetter dial gauge

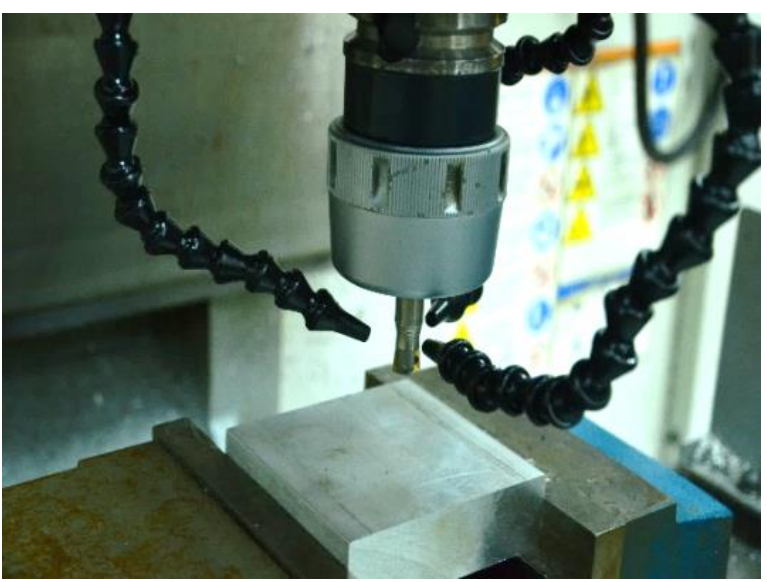

(b) Setting of the MQL nozzle around the machine spindle

Figure 2. Setup of workpiece.

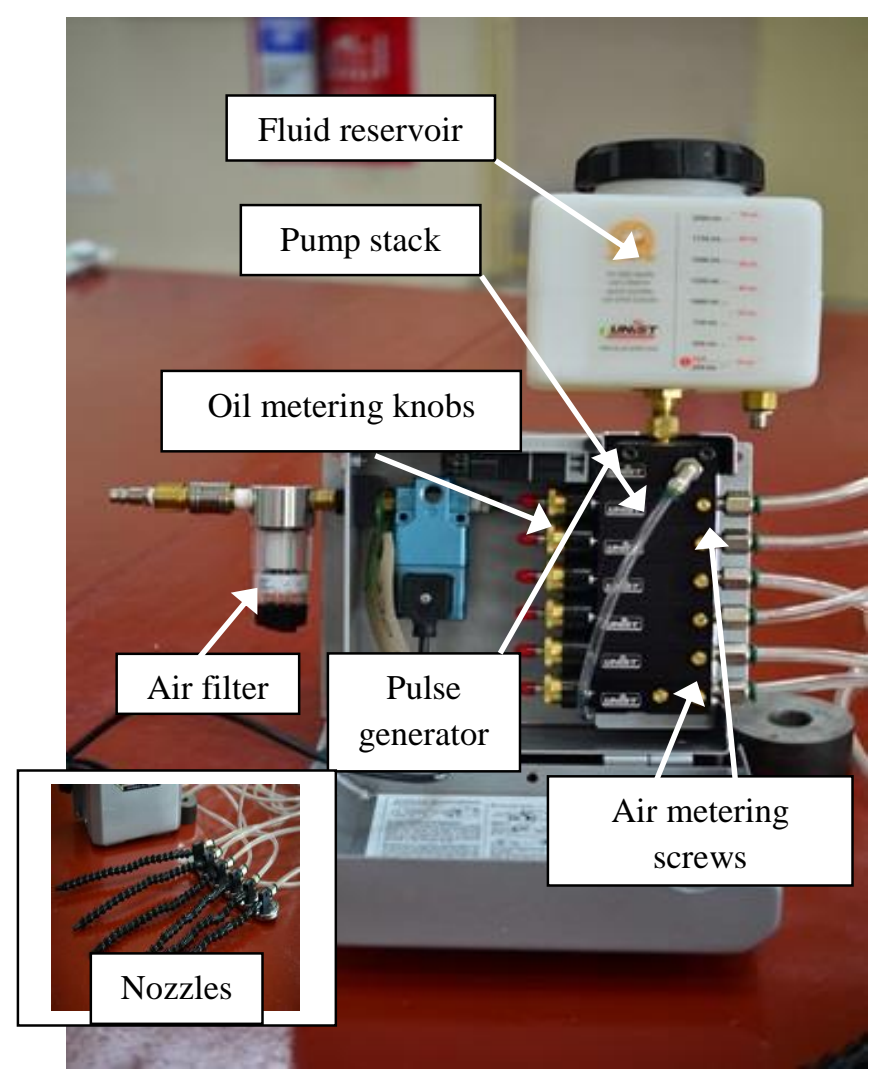

Figure 3. MQL system and setting. 


\section{RESULTS AND DISCUSSION}

\section{Significance of Input Parameters}

Significance of input parameters is determined based on the difference in the mean of two groups of experimental design at high and low levels. The relative importance and rankings of main parameters and their interactions with respect to response variables are evaluated by determining the parameters effect size using DOE as shown in Figure 4. The overall pie-chart and table (Figure 4 Table 2) show the contribution of each input variable relative to the overall response. From the student chart of surface roughness, it is obvious that the depth of cut and table feed rate are the most contributing factors, while for material removal rate the most contributing factor is depth of cut. In case of flank wear, feed rate is the most effective parameter.

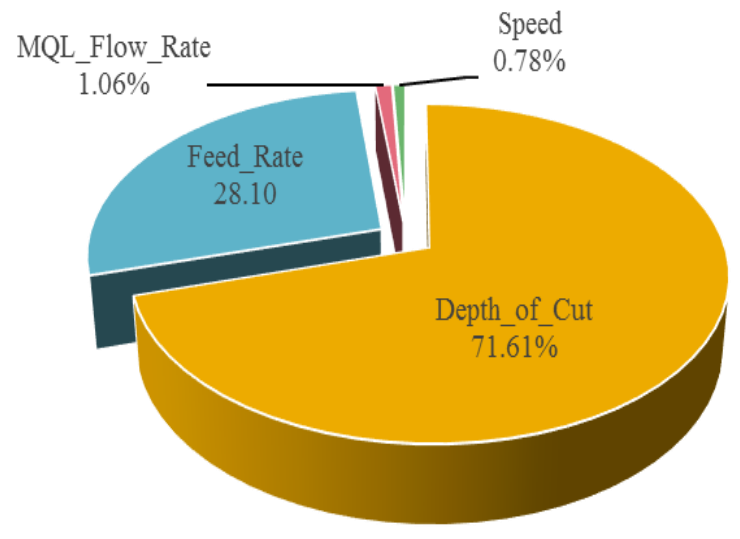

(a) Material removal rate

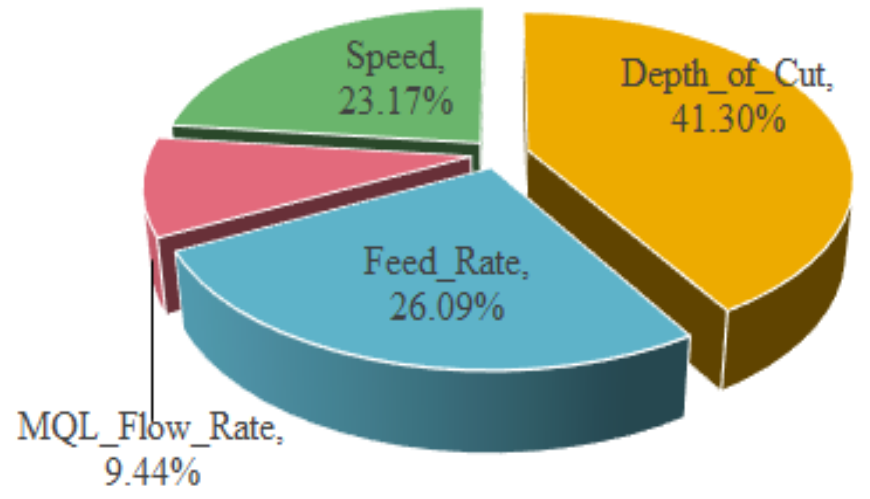

(b) Surface roughness

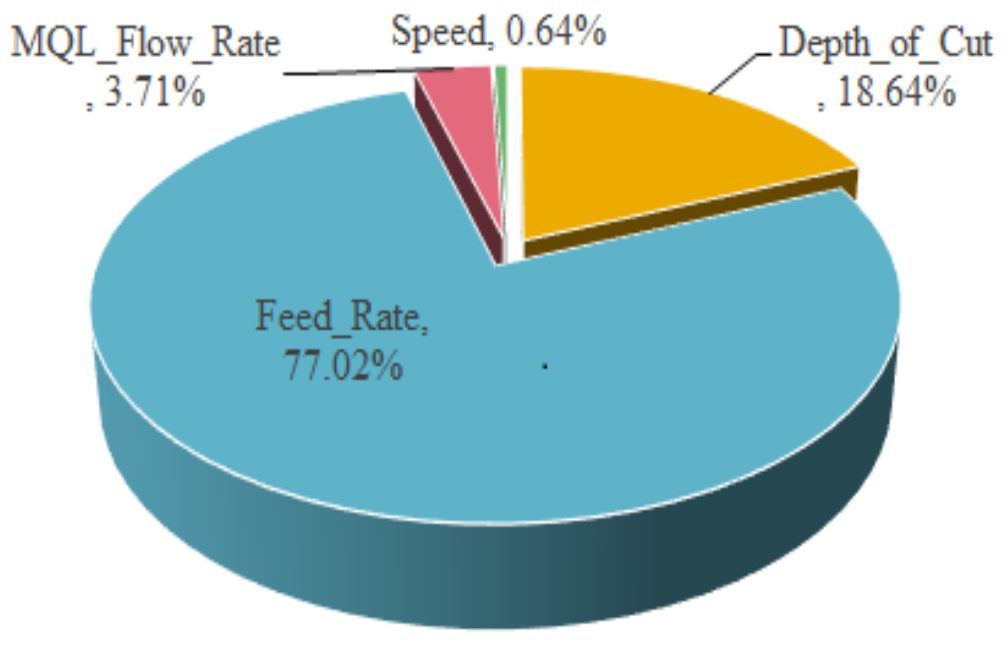

(c) Flank wear

Figure 4. Significance of input parameters for response variables. 
Table 2. Significance of parameters.

\begin{tabular}{lccc}
\hline & Material removal rate & Surface roughness & Flank wear \\
\hline Speed, rpm & $0.78 \%$ & $23.17 \%$ & $0.64 \%$ \\
Table feed rate, $\mathrm{mm} / \mathrm{min}$ & $28.10 \%$ & $26.09 \%$ & $77.02 \%$ \\
Depth of cut, $\mathrm{mm}$ & $71.61 \%$ & $41.3 \%$ & $18.64 \%$ \\
MQL flow rate, $\mathrm{ml} / \mathrm{min}$ & $1.06 \%$ & $9.44 \%$ & $3.71 \%$ \\
\hline
\end{tabular}

A multi-objective genetic algorithm mode II (MOGA-II) is used for optimization. The design of experiments serve as "initial population". Initial population consists of sets of chromosomes. The chromosomes evolve during several iterations called generations [54]. The best individuals are evaluated, recombined and mutated to constitute a new population. MOGA was first generation genetic algorithm [55], while MOGA-II is a second generation evolutionary algorithm with elitism. The basic concept of using genetic algorithm for optimization is that the genetic collection of a given population contains better solutions to a given problem. The general operators applied in evolutionary algorithms are selection, mutation and cross-over. MOGA-II algorithm implements a fourth operator i.e. multi-search elitism. Selection operator shifts designs to the next generation, selection being based on the best fitness of the function. Designs with higher fitness value are more likely to be replicated into the next generation ensuring a higher survival probability for the more fit solutions. The new generations are generated utilizing the crossover and mutation technique. The crossover split into two chromosomes and then combines one half of each chromosome with the other pair. Mutation involves flipping a single bit of chromosomes [54]. The chromosomes are then evaluated against certain fitness criteria and the best ones are retained while the others are rejected. Elitism operator is able to preserve all non-dominated solutions without avoiding from the initial population thus enhancing the convergence speed.

The multi-objective optimization is performed using the genetic algorithm MOGA-II. Algorithm is stopped after 100 generations. Pareto solutions are selected from the total feasible solutions obtained after 100 generations. The Pareto approach to optimization is aimed to identify the set of parameters that characterize a design and beyond which no aspect of performance can be improved without compromising another. The results of multi-objective optimization is a group of designs that dominate the others. This group is known as the Pareto optimal set [56]. All the Pareto designs obtained from the optimization process are considered as equally desirable from the mathematical point of view. These designs are large in number, therefore, selection of final design configuration is essential for putting into practice. In order to find out single best solution, genetic-algorithm based on MCDM technique is used with the Pareto frontier as search space and assigning the preference weightage to each attribute. A utility function is generated on the basis of weightage assigned and all the Pareto designs are ranked. Multi-objective problem is reduced to a single-objective problem through a weighted utility function which satisfies all preferences in terms of designs-attribute relationships. The MCDM method involves attribute setting, preference weightage assignment, GA-based ranking of the individuals according to the fitness evaluation criteria.

\section{Objective Functions}

In order to optimize a machining operation some objective functions are to be defined. The optimization problem for the study is a multi-objective optimization problem. Machining operations can be very efficient when optimum cutting parameters are used. Optimum cutting 
conditions need to be determined before the start of production. Optimization is done to determine the best combination of parameters for the end milling process. The independent variables in this study which are used for optimization of the machining process are axial depth of cut, feed rate, speed and minimum quantity lubricant flow rate. The arithmetical mean deviation of the assessed profile, Ra, material removal rate and flank wear are used as the objective functions in this single pass milling parameter optimization problem. Minimum surface roughness is not only a quality indicator but also the final stage in controlling the machining performance and the operation cost [25]. Surface roughness is measured as arithmetical mean deviation of all the measured values in the assessed profile from the mean line of that profile. A section of standard length $(17 \mathrm{~mm})$, determined from the capability of the perthometer available, is sampled from the mean line on the roughness chart. Maximizing the material removal rate is taken as another objective function which serves as the basis of optimization. Therefore the two objectives are conflicting; i.e., one has to be compromised in order to achieve a gain in the other. The third objective function is to minimize the flank wear.

\section{Machining Constraints}

In addition to objective functions, the machining operations are effectively defined by the constraints. These constraints are defined by the process capabilities and the product requirements. Process capabilities include the actual machine conditions, allowable cutting spindle speeds, feed rates, maximum heat generation and maximum machine power, while the product requirements include the product surface finish requirements and the required material removal rate. In order to perform an effective optimization, these constraints must be fully satisfied. The solutions as the optimal cutting parameters for the study are constrained by some boundary conditions. In the case proposed, the boundary constraints are set within the experimental scope.

The constraints considered in this study are given by Eq. (1) to Eq. (6).

Minimize surface roughness, $R_{a}=\mathrm{fn}$ (Speed,Feed rate, depth of cut, MQL Flow rate) ;

Maximize material removal rate, $M R R=\mathrm{fn}$ (Speed,Feed rate, depth of cut, MQL Flow rate);

Minimize the flank wear, $F W=\mathrm{fn}$ (Speed,Feed rate, depth of cut, MQLFlow rate)

Subject to:

1. Speed $_{\text {min }} \leq$ Speed $\leq$ Speed $_{\text {max }}$

2. Feed rate $_{\text {min }} \leq$ Feed rate $\leq$ Feed rate $_{\max }$

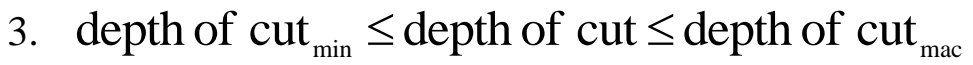

4. MQL Flow rate $_{\text {min }} \leq \mathrm{MQL}$ Flow rate $\leq \mathrm{MQL}$ Flow rate $_{\text {max }}$ while

5. $R_{a \min } \leq R_{a} \leq R_{a \max }$

6. $\mathrm{MRR}_{\text {min }} \leq \mathrm{MRR} \leq \mathrm{MRR}_{\text {max }}$

7. $\mathrm{F} W_{\min } \leq F \mathrm{~W} \leq \mathrm{F} W_{\max }$

In this study, optimization of the machining process is performed using the multi-objective genetic algorithm (MOGA-II) strategy. Genetic algorithms have been used in function 
optimization since their inception to optimize large poorly understood problems that arise in many areas of science and engineering [57].

\section{Pareto Designs}

The outcome of the primary optimization is a set of optimal feasible solutions which shows the trade-off between the two objectives, which is called a Pareto set. The use of Pareto optimal designs has several advantages. Because these designs are selected from feasible designs, the feasibility of the optimal design is ensured. The Pareto approach to optimization is aimed at identifying the set of parameters that characterize a design, and beyond which no aspect of performance can be improved without compromising another. The method provides a means to understand the trade-offs between the conflicting requirements that the designer must address [28]. In the current study, 52 Pareto designs are obtained. The set of all Pareto optimal points is known as the Pareto frontier. The Pareto frontier for the current designs is plotted in Figure 4.

Table 3. Optimum cutting parameters and response variables.

\begin{tabular}{lccc}
\hline Input Variables & \multicolumn{2}{c}{ Initial values } & Optimum cutting variables \\
\hline & Minimum & Maximum & \\
\hline Cutting speed, $\mathrm{rpm}$ & 5252 & 5548 & 5252 \\
Table feed rate, $\mathrm{mm} / \mathrm{min}$ & 288 & 469 & 311.0 \\
Depth of cut, $\mathrm{mm}$ & 0.52 & 3.48 & 3.472 \\
MQL flow rate, $\mathrm{ml} / \mathrm{min}$ & 0.39 & 0.90 & 0.44
\end{tabular}

\begin{tabular}{lccc}
\hline \multicolumn{1}{c}{ Objective Functions } & Constraints & \multicolumn{2}{c}{$\begin{array}{c}\text { Optimized } \\
\text { response }\end{array}$} \\
\hline Minimize surface roughness, $\mu \mathrm{m}$ & $0.432<\mathrm{SR}, \mu \mathrm{m}<2.103$ & 0.543 \\
\hline Minimize flank wear, $\mu \mathrm{m}$ & $15.88<\mathrm{FW}, \mu \mathrm{m}<38.4$ & 15.95 \\
\hline Maximize material removal & rate, & $\begin{array}{c}2116.6<\mathrm{MRR}, \\
\mu \mathrm{m}<15444.0\end{array}$ \\
$\mathrm{~mm}^{3} / \mathrm{min}$ & & \multicolumn{2}{c}{15173} \\
\hline
\end{tabular}

\section{Optimization Results}

The results of multi-objective optimization are a set of 1896 feasible designs from a total of 2600 designs out of which 39 designs belong to the Pareto frontier that is the set of non-dominated Pareto optimal solutions. The distributions of Pareto designs against the input design variables are shown by bubble charts. In the bubble chart $x$-axis represents the design variable while on $y$-axis the one response variable i.e. surface roughness in this case is plotted, while the bubble diameter and bubble colour indicate respectively the material removal rate the and flank wear. Figure 5 shows the distribution of Pareto optimal designs with respect to input variables. Figure 5(a) shows the distribution of Pareto designs with the increase in depth of cut. Most of the Pareto designs lie in the whole range of depth of cut with best designs from $0.5 \mathrm{~mm}$ to $1.7 \mathrm{~mm}$. For the feed rate, the distribution of Pareto designs (Figure 5(b)) shows most of the designs are obtained between 280 $\mathrm{mm} / \mathrm{min}$ to $300 \mathrm{~mm} / \mathrm{min}$. Some designs with lower surface roughness and flank wear are found on higher feed rates as well. Almost all of the Pareto designs are found at the minimum speed as shown in Figure 5(c). Most feasible Pareto designs are obtained between MQL flow rate ranges of $0.77 \mathrm{ml} / \mathrm{min}$ to $0.80 \mathrm{ml} / \mathrm{min}$ as given in Figure 5(d). In order to select a single best compromised solution among the solutions located on the Pareto frontiers, the multi-criteria decision making 
technique is employed. Depending on the non-preference based relation among the response variables, all the solutions are classified with rank values. A comparison between the initial and optimal solutions in terms of both independent variables, objectives parameters and constraints is presented in Table 3. Surface roughness for uncoated tungsten carbide insert in conventional MQL increases up to $25.7 \%$ higher as compared to initial minimum value however the surface roughness values remain lower than the highest value by $74.2 \%$. An increase in flank wear equal to $1.0 \%$ with respect to minimum value used while the improvement is almost $58.4 \%$ with respect to maximum flank wear value. The optimum value of material removal rate is increased much higher with respect to minimum measured value.
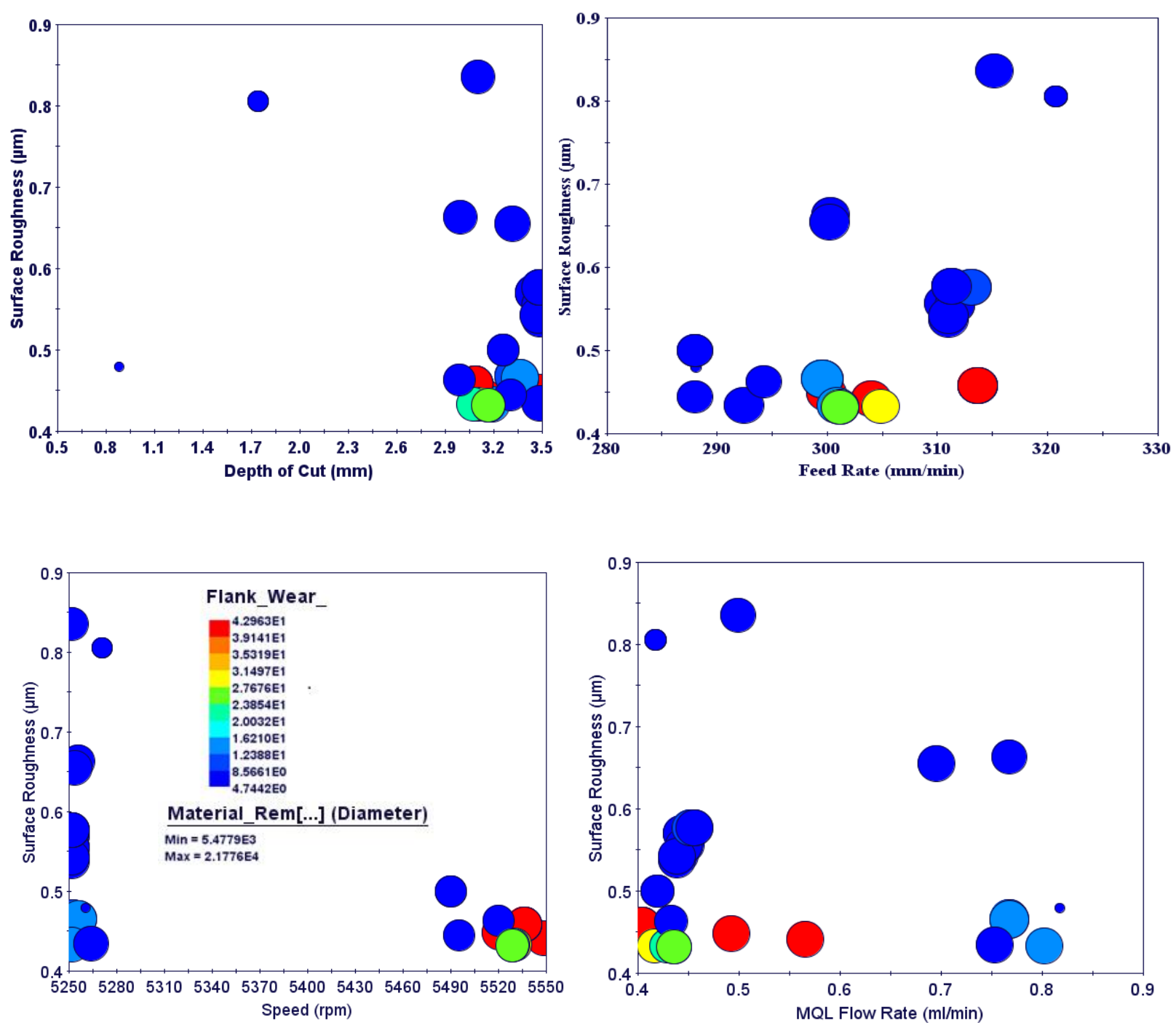

Figure 5. Bubble chart showing Pareto designs distribution with respect to input parameters. 


\section{CONCLUSIONS}

In the foregoing study multi-objective optimization of a CNC end milling operation with minimum quantity lubrication is performed by applying a genetic algorithm. The surface roughness, material removal rate and flank wear of the tool are the conflicting responses which are to be optimized. From among the feasible designs, Pareto designs are selected for further study. A multi-criteria decision making algorithm is run for the Pareto designs. The designs are ranked according to their fitness for the optimum criteria. Three objective functions are given equal weightage and the optimum design is obtained. The best design obtained for the equal weightage case is the design at $5252 \mathrm{rpm}$, with a feed rate of $311 \mathrm{~mm} / \mathrm{min}$, a depth of cut of $3.47 \mathrm{~mm}$ and MQL flow rate at $0.44 \mathrm{ml} / \mathrm{min}$. The optimum values for surface roughness is $0.543 \mu \mathrm{m}$; material removal rate is found to $15173 \mathrm{~mm}^{3} / \mathrm{min}$ while optimized flank wear is $15.95 \mu \mathrm{m}$. A range of feasible designs of experiment thus obtained as well as the selected optimized design can serve as future benchmark for manufacturing practices within the defined domain.

\section{ACKNOWLEDGEMENTS}

The authors would like to express their gratitude to Universiti Malaysia Pahang (UMP) for providing laboratory facilities and financial support under project No. RDU110110.

\section{REFERENCES}

[1] Najiha M, Rahman M, Kadirgama K. Performance of water-based $\mathrm{TiO}_{2}$ nanofluid during the minimum quantity lubrication machining of aluminium alloy, AA6061-T6. Journal of Cleaner Production. 2016; In press, doi:10.1016/j.jclepro.2015.12.015.

[2] Hanafi I, Khamlichi A, Cabrera FM, Almansa E. Optimization of cutting conditions for sustainable machining of PEEK-CF30 using TiN tools. Journal of Cleaner Production. 2012;33:1-9.

[3] Fratila DF. Research of environment-friendly techniques influence on gear accuracy in context of sustainable manufacturing Proceedings of the Romanian Academy, Series A2013. p. 56-63.

[4] Marksberry PW, Jawahir IS. A comprehensive tool-wear/tool-life performance model in the evaluation of NDM (near dry machining) for sustainable manufacturing. . International Journal of Machine Tools and Manufacture. 2008;48:878-86.

[5] Najiha MS, Rahman MM, Kamal M, Yusoff AR, Kadirgama K. Minimum Quantity Lubricant Flow Analysis in End Milling Processes: A Computational Fluid Dynamics Approach. Journal of Mechanical Engineering and Sciences. 2012;3:340-5.

[6] Attanasio A, Gelfi M, Giardini C, Remino C. Minimal quantity lubrication in turning: effect on tool wear. Wear. 2006;260:333-8.

[7] Lawal SA, Chouhury IA, Nukman Y. A critical assessment of lubrication techniques in machining processes: a case for minimum quantity lubrication using vegetable oil-based lubricant. Journal of Cleaner Production. 2013;41:210-21.

[8] Li C, Zhao H, D Jia, Zhang D, Hou Y. Experimental study on generation mechanism and influencing factors of metal machining fluid oil mist microparticles. International Journal of Control and Automation. 2014;7:423-38. 
[9] Rahman MM, Yusoff AR, Kadirgama K. Investigation of flow behavior in minimum quantity lubrication nozzle for end milling processes. International Journal of Automotive and Mechanical Engineering. 2012;6:768-76.

[10] Puvanesan M, Rahman MM, Najiha MS, Kadirgama K. Experimental investigation of minimum quantity lubrication on tool wear in aluminum alloy 6061-T6 using different cutting tools. International Journal of Automotive and Mechanical Engineering. 2014;9:1538-49.

[11] Najiha MS, Rahman MM. Experimental study on minimum quantity lubrication in end milling of AA6061-T6 using tialn coated carbide tools. International Journal of Automotive and Mechanical Engineering. 2015;11:2771-85.

[12] Thakur DG, Ramamoorthy B, Vijayaraghavan L. Optimization of minimum quantity lubrication parameters in high speed turning of superalloy Inconel 718 for sustainable development. World Academy of Science, Engineering and Technology. 2009;54():224-6.

[13] Dhar NR, Islam MW, Islam S, Mithu MAH. The influence of minimum quantity of lubrication (MQL) on cutting temperature, chip and dimensional accuracy in turning AISI1040 steel. Journal of Materials Processing Technology. 2006;171:93-9.

[14] Najiha MS, Rahman MM, Yusoff AR, Kadirgama K. Investigation of flow behavior in Mminimum quantity lubrication nozzle for end milling processes. International Journal of Automotive and Mechanical Engineering. 2012;6:768-76.

[15] Klocke F, Eisenblatter G. Dry cutting. Annals of CIRP 1997;46:519-26.

[16] MaClure TF, Adams R, Gugger MD. Comparison of flood vs. microlubrication on machining performance. http://wwwunistcom/techsolvehtml. 2007.

[17] Sreejith PS, Ngoi BKA. Dry machining: machining of the future. Journal of Material Processing Technology. 2000; 101:287-91.

[18] Braga DU, Diniz AE, Miranda GWA, Coppini NL. Using a minimum quantity of lubricant (MQL) and a diamond coated tool in the drilling of aluminum-silicon alloys. Journal of Materials Processing Technology. 2002;122:127-38.

[19] Davim JP, Sreejith PS, Silva J. Turning of brasses using minimum quantity of lubricant and flooded lubricant conditions. Materials and Manufacturing Processes. 2007;22:45-50.

[20] Filipovic A, Stephenson DA. Minimum quantity lubrication applications in automotive power-train machining. Machining Science and Technology. 2006;10:3-22.

[21] Rahman M, Kumar AS, Salam MU. Experimental evaluation on the effect of minimal quantities of lubricant in milling. International Journal of Machine Tools and Manufacture. 2002;42:539-47.

[22] Lacalle LNLD, Angulo C, Lamikiz A, Sanchez JA. Experimental and numerical investigation of the effect of spray cutting fluids in high speed milling. Journal of Materials Processing Technology. 2006;172:11-5.

[23] Liao YS, Lin HM. Mechanism of minimum quantity lubrication in high speed milling of hardened steel. International Journal of Machine Tools and Manufacture. 2007;47:1660-6.

[24] Su YL, Liu TH, Su CT, Yao SH, Kao WH, Cheng KW. Wear of CrC-coated carbide tools in dry machining. Journal of Materials Processing Technology. 2006;171:108-17.

[25] Najiha MS, Rahman MM, Yusoff AR. Modeling of the End Milling Process for Aluminum Alloy AA6061t6 using HSS Tool. International Journal of Automotive and Mechanical Engineering. 2013;8:1140-50. 
[26] Najiha M, Rahman M, Ahmad Razlan Y. Modeling of the End Milling Process for Aluminium Alloy AA6061t6 Using HSS Tool. International Journal of Automotive and Mechanical Engineering. 2013.

[27] Kamata Y, Obikawa T. High speed MQL finish-turning of Inconel 718 with different coated tools. Journalof Material Processing Technology. 2007;192:281-6.

[28] Baheti U, Guo C, Malkin S. Environmentally conscious cooling and lubrication for grinding. In: Performance PotISoIMT, editor.1998. p. 643-54.

[29] Hafenbraedl D, Malkin S. Environmentally-conscious minimum quantity lubrication (MQL) for internal cylindrical grinding. Transactions of North American Manufacturing Research Institution/Society of Manufacturing Engineers (NAMRI/SME)2000. p. 149-54.

[30] Silva LR, Bianchi EC, Catai RE, Fusse RY, Franca TV. Study on the behavior of the minimum quantity lubricant - MQL technique under different lubricating and cooling conditions when grinding ABNT 4340 steel. Journal of the Brazilian Society of Mechanical Sciences and Engineering 2005;27:192-9.

[31] Sahid NSM, Rahman MM, Kadirgama K. Neural Network Modeling of Grinding Parameters of Ductile Cast Iron Using Minimum Quantity Lubrication. International Journal of Automotive and Mechanical Engineering. 2015;11:2608-21.

[32] Pusavec F, Krajnik P, Kopac J. Transitioning to sustainable production-Part II: evaluation of sustainable machining technologies. Journal of Cleaner Production. 2010;18:1211-21.

[33] Shen B, Shih AJ, Simon CT. Application of nanofluids in minimum quantity lubrication grinding. Tribology Transactions. 2008;51:730-7.

[34] Lee PH, Nam TS, Li C, Lee SW. Environmentally-friendly nano-fluid minimum quantity lubrication (MQL) meso-scale grinding process using nano-diamond particles. International Conference on Manufacturing Automation: IEEE Computer Society; 2010.

[35] Nam TS, Lee PH, Lee SW. Experimental characterization of micro-drilling process using nanofluid minimum quantity lubrication. International Journal of Machine Tools \& Manufacture. 2011;51:649-52.

[36] Rao SN, Satyanarayana B, Venkatasubbaiah K. On line tool wear prediction models in minimum quantity lubrication Global Journal of Researches in Engineering: Automotive Engineering. 2011;11:13-8.

[37] Park KH, Ewald B, Kwon PY. Effect of nano-enhanced lubricant in minimum quantity lubrication balling milling. Journal of Tribology. 2011;133:pp.8.

[38] Rahmati B, Sarhan AAD, Sayuti M. Investigating the optimum molybdenum disulfide (MoS2) nanolubrication parameters in CNC milling of AL6061-T6 alloy. International Journal of Advance Manufacturing Technology. 2014;70:1143-55.

[39] Sayuti M, Sarhan AAD, Hamdi M. An investigation of optimum SiO2 nanolubrication parameters in end milling of aerospace Al6061-T6 alloy. International Journal of Advance Manufacturing Technology. 2013;67:833-49.

[40] Boswell B, Voges E. The effect of combined cold air and minimum liquid cooling on end milling. International Conference on Mechanical, Industrial, and Manufacturing Engineering. Ming Ma (ed) ed. Melbourne, Vic. Australia: Information Engineering Research Institute; 2011. p. 54-7.

[41] Boswell B, Voges E. The effect of combined cold air and minimum liquid cooling on end milling. Advances in Mechanical Engineering. 2012;2.

[42] Boswell B, Islam MN. The Challenge of Adopting Minimal Quantities of Lubrication for End Milling Aluminium. In: (eds.) G-CYea, editor. Lecture Notes in Electrical 
Engineering, IAENG Transactions on Engineering Technologies. Australia: Springer Science+Business Media Dordrecht; 2013.

[43] Boubekri N, Shaikh V, Foster PR. A technology enabler for green machining: minimum quantity lubrication (MQL). Journal of Manufacturing Technology Management. 2010;21:556-66.

[44] Ariff TF, Paimin MF, Hassan A. Dry machining of T6061 aluminium alloy using Titanium Nitride (TiN) and Titanium Carbonitride (TiCN) coated tools Applied Mechanics and Materials. 2013;284-287:291-5.

[45] Tosun N, Huseyinoglu M. Effect of MQL on surface roughness in milling of AA7075-T6. Materials and Manufacturing Processes. 2010;25:793-8.

[46] Srikanth KS, Jaisankar V, Vasisht JS. Evaluation of tool wear and surface finish of AISI 3161 stainless steel using nano cutting environment. Proceedings of 5th IRF International Conference. India2014.

[47] Kotaiah RK, Srinivas J, Babu KJ, Kolla S. Prediction of optimal cutting states during inward turning: An experimental approach. Materials and Manufacturing Processes. 2010;25:432-41.

[48] Itoigawa F, Childs THC, Nakamura T, Belluco W. Effects and mechanisms in minimal quantity lubrication machining of an aluminum alloy. Wear. 2006;260:339-44.

[49] Ahmad N, Tanaka T, Saito Y. Optimization of cutting parameters for end milling operation by soap based genetic algorithm. Proceedings of the International Conference on Mechanical Engineering 2005, (ICME2005). Dhaka, Bangladesh2005. p. 5.

[50] Lakshmi VVK, Subbaiah KV. Modelling and optimization of process parameters during end milling of hardened steel. International Journal of Engineering Research and Applications. 2012;2:674-9.

[51] Kumar N, Chhabra KK. Trade off among conflicting multi objectives of CNC end milling process for LM6 Al/SiC. International Journal of Science and Research (IJSR). 2014;3:138-45.

[52] Ponnala WM, Murthy KLN. Modeling and optimization of end milling machining process. International Journal of Engineering Research and Technology. 2012;1:430-47.

[53] Goel T, Vaidyanathan R, Haftka RT, Shyy W, Queipo NV, Tucker K. Response surface approximation of Pareto optimal front in multi-objective optimization. Computer Methods in Applied Mechanics and Engineering. 2007;196:879-93.

[54] Routara BC, Sahoo AK, Parida K, Padhi PC. Response surface methodology and genetic algorithm used to optimize the cutting condition for surface roughness parameters in CNC turning. Procedia Engineering. 2012;38:1893 - 904.

[55] Fonseca CM, Fleming PJ. Genetic algorithms for multi-objective optimization: formulation, discussion and generalization in Genetic algorithms. In: (Ed.) SF, editor. Proceedings of the Fifth International Conference. San Mateo, CA: Morgan Kauffman; 1993.

[56] Pinto F. Application of evolutionary techniques to energy transfer efficiency in heat transfer problems and low consumption buildings [Ph.D.]. Italy: University of Bologna 2007.

[57] Adeli H, Chang N. Integrated genetic algorithm for optimization of space structures. Journal of Aerospace Engineering. 1993;6:315-28. 